\title{
Phytochemical Analysis of Guiera senegalensis J.F. Gmel Extract and its Anti-Plasmodial Properties on Wister Albino Mice via Oral Route
}

\author{
I.H. Ifijen ${ }^{1 *}$, A.U. Mamza ${ }^{2}$, K.A. Fasina ${ }^{3}$, J.I. Omoruyi ${ }^{4}$, E.U. Ikhuoria ${ }^{2}$ \\ ${ }^{1}$ Research Operations Department, Rubber Research Institute of Nigeria, PMB 1049, Benin City, \\ Edo State, Nigeria \\ ${ }^{2}$ Department of Chemistry, Faculty of Physical Sciences, University of Benin, PMB 3011,Benin- \\ City, Edo State, Nigeria \\ ${ }^{3}$ Biotechnology Division, Rubber Research Institute of Nigeria, PMB 1049, Benin City, Edo State, \\ Nigeria \\ ${ }^{4}$ Crop Improvement and Management Department, Rubber Research Institute of Nigeria, PMB \\ 1049, Benin City, Edo State, Nigeria \\ "larylans4u@yahoo.com
}

Keywords: Guiera senegalensi; anti-malarial; prophylactic; curative; phytochemical; acute toxicity

\begin{abstract}
Guiera senegalensis J.F. Gmel (Combretaceae) is acclaimed as a common herbal antipyretic and anti-malarial among some tribal groups in northern Nigeria. The aim of this study was to investigate the phytochemical constituents, antiplasmodial activity and the acute toxicity of G. senegalensis on mammalian cells. Aqueous ethanolic leaf extracts (AELE) of the plant were tested for the presence of phytochemicals including alkaloids, carbohydrates, flavonoids, cardiac glycoside, glycosides, phenolic acids, saponins and tannins using standard techniques. The AELE was then screened for acute toxicity on Wister albino mice (WAM) weighing between 30-35g and its antiplasmodial activity against Plasmodium berghei (the causative agent of malaria in some mammals). Phytochemical screening revealed the presence of carbohydrate, phenols, flavonoids, abundant tannins, alkaloid, saponins with the absence of cardiac glycosides in the AELE. Also, it was observed that $G$. senegalensis extracts had no toxic effect on the WAM across administered doses of 100, 200 and $400 \mathrm{mg} / \mathrm{kg}$. From the prophylactic study, it was found that the AELE dosage of $200 \mathrm{mg} / \mathrm{kg}$ was most effective in the inhibition of $P$. berghei when compared with the control than other dosages tested (100 and $400 \mathrm{mg} / \mathrm{kg}$ ). The extract also exhibited a better anti-plasmodial property $(80 \%$ inhibition) in the curative study compared to the standard drug (Chloroquine diphosphate) $(52 \%)$, inhibiting at the graded doses of AELE. It can, therefore, be concluded from this study that $G$. senegalensis extract possesses essential phytochemicals, resulting in antiplasmodial effect against Plasmodium berghei.
\end{abstract}

\subsection{Introduction}

Phytochemicals are bioactive non-nutrient compounds present in fruits, vegetables, grains, medicinal plants as well as other plants [1]. More than 10,000 phytochemicals have been extracted and identified including tannins, triterpenoids, glycosides, steroids, flavones, saponins, alkaloids and steroids [2]. Many studies have demonstrated the strong medicinal effects of phytochemicals for treating chronic diseases $[1,3,4]$. It has been suggested that phytochemicals combat diseases mainly through their high antioxidant activity, in response to the high production of oxidants during a pathogenic invasion of host tissues [2]. A previous study has also established that phytochemicals have anti-oxidant activities in vitro as well as in vivo human studies [1].

One prevalent disease in the world, according to the World Health Organization, is Malaria. It is a pandemic affecting over 100 countries in Southeast Asia, South America and Africa [5] and it is caused by a parasitic protozoan Plasmodium spp. Malaria is transmitted by a vector, the female Anopheles mosquito [5]. Over 2.4 million people are presently at risk globally, and the WHO in the World Malaria Report of 2009 [6] reported mortality of about 1 million people every year globally, 
and about 250 million asymptomatic and symptomatic carriers. Malaria has been eradicated in most developed countries like the USA and the UK, mainly by breaking the parasite's life cycle, but it still poses a great deal of economic and health trauma to many developing countries.

Bourdy et al. [7] said that 11 of the antimalaria parasites presently included in the WHO therapeutic regimen for malaria treatment were either designed based on pharmacophores from natural products or are even natural products themselves. These natural remedies have now dominated primary health care in over $80 \%$ of the world population[8]. Guiera senegalensis, also known as "Sabara" (in the Hausa language) and "Kishishi" (in Kanuri language) has now been used in traditional medicine for the treatment of many diseases including cough, respiratory congestion and fever [9]. Aniagu et al. [10] used extracts of this plant's leaves, branches, bark and roots for the treatment of stomach pains and dysentery, while its use in the treatment of syphilis, beriberi, leprosy and impotence has also been reported [11].

G. senegalensisis and is widely distributed in the savannah region of west and central Africa, in countries like Senegal, Niger, Nigeria, Gambia, Ghana and Burkina Faso [12]. It is a shrub, whose leaves are 3 to $5 \mathrm{~cm}$ long, and 1.5 to $3.0 \mathrm{~cm}$ broad; arranged in opposing positions to each other on the stem. It can grow up to 3 to $5 \mathrm{~m}$ tall. Diatta et al. [13] recorded its use against asthmatic cough, for easing breath, treating lung cancer and bronchial disorders. Azas et al. [14] reported its use for treating malaria, thus opening a new frontier in the search for anti-malarial therapies. Since malaria is a pandemic affecting infants, children, adults spanning multiple continents resulting in widespread mortalities, a breakthrough anti-malarial product from $G$. senegalensis will be greatly welcome in the international market. This study, therefore, was aimed at screening the aqueous extracts of Guiera senegalensis leaves for its phytochemical constituents, as well as its antiplasmodial potentials on Albino Wister mice.

\section{Materials and Methods}

Fresh leaves were collected from Dalori Town of Konduga Local Government, Borno State, Nigeria according to WHO, 2003 [15]. The leaves were identified and authenticated by a plant taxonomist from the Department of Biological Sciences, University of Benin, Benin City, Edo State, Nigeria. The fresh leaves of G. senegalensis were air dried and ground to powdered form using a mechanical grinder and kept in cellophane bag at $4{ }^{\circ} \mathrm{C}$ before extraction as described by Oshobu and Geidam [15].

\subsection{Plant Extraction}

The pulverized plant material $(750 \mathrm{~g})$ was exhaustively extracted using maceration method [16] with ethanol. The extracts were concentrated in vacuum at $40^{\circ} \mathrm{C}$ using a rotatory evaporator and later air-dried to give dried crude extracts. The extracts were weighed and their weights recorded $(18.84 \mathrm{~g})$.

\subsection{Phytochemical Screening}

Phytochemical analysis of the extract was carried out according to the methods given by a previous publication [17]. Qualitative analysis of the phytochemicals was carried out using the methods described by [17] for tannins, [17] for saponins, [17] for flavonoids, Obasi et al. [17] for carbohydrates, phenolic compounds and alkaloids, and Ayoola et al. [17] for cardiac glycosides. Their presence in the extracts was indicated based on their activity in solution; $(+++)$ Very strong positive, $(++)$ positive, $(+)$ Trace and (-) Negative where there was no reaction.

\subsection{Determination of Phenolic and Flavonoid Concentrations in the Plant leaf extract}

The phenolic contents in the three plant extracts were determined using the Folin-Ciocalteu method [17]. $100 \mu \mathrm{l}$ of Folin-Ciocalteu solution was added to $500 \mu \mathrm{l}$ of each extract and placed in the incubator in the dark at room temperature $\left(22-25^{\circ} \mathrm{C}\right)$. After 15 minutes incubation, $2500 \mu 1$ of saturated sodium carbonate was added and incubated for 30 more minutes at room temperature. The 
absorbance of the solution was read at 760nm using a spectrophotometer (GeneSyn 20, Thermo, USA), and the concentration was read from the standard curve constructed using gallic acid as the standard. The concentration of the phenolic compounds was estimated in triplicates. The results were recorded as mean values and expressed as $\mathrm{mg}$ of Gallic acid equivalent (GAE)/g of dry extract [17].

The flavonoid content was quantified using the aluminum chloride colorimetric method as described by Chang et al. [17] with some modifications. Each extract $(1 \mathrm{ml})$ in methanol was separately mixed with $1 \mathrm{ml}$ of methanol, $0.5 \mathrm{ml}$ of $1.2 \%$ Aluminum chloride, $0.5 \mathrm{ml}$ of $0.12 \mathrm{M}$ potassium acetate and $2.8 \mathrm{ml}$ of distilled water. Mixtures remained at room temperature for $30 \mathrm{~min}$; the absorbance of the reaction mixture was measured at $415 \mathrm{~nm}$ using a spectrophotometer (GeneSyn 20, Thermo, USA). Total flavonoid content of the extract was expressed as milligram equivalents to quercetin per gram (mg QE/g) dry weight of the extract [17].

\subsection{Experimental Animals}

The animals used in this study were specific-pathogen-free mice (Mus musculus), aged 6-8 weeks old and weighed 30-35 g. They were purchased from the Department of Biochemistry, Animal House, University of Benin, Benin City, Edo State, Nigeria. They were kept at room temperature $\left(22-25^{\circ} \mathrm{C}\right)$ with 12 hours light/dark cycle and given standard mouse pellets with water ad libitum. They were acclimatized for 14 days. Procedures of the animal experiments were ratified by the Ethical Committee on Animal Experimentation, Faculty of Pharmacy, University of Benin, Benin City, Edo State, Nigeria.

\subsection{Malaria parasite (Plasmodium berghei)}

Chloroquine-sensitive Plasmodium berghei strain ANKA (PbANKA) was used for the experiment. The parasites were carefully inoculated into the mice by intraperitoneal (IP) passage to ensure their survival after inoculation. Parasitemia as a result of PbANKA infection was daily monitored by microscopic examination of Giemsa stained thin blood.

\subsection{Treatment of the Animals}

The mice were apportioned into Five (5) groups of five (5) animals per group for the prophylactic test. The same experimental design was also used for the Curative Test. A standard anti-malarial drug Chloroquine disulphate was used as Positive control in both experiments, while distilled water was used as the negative control. The treatments for the experiment were aqueous ethanol extracts of G. senegalensis at different concentrations (100, 200 and $400 \mathrm{mg} / \mathrm{kg})$.

Table 1: Treatment for Prophylactic and Curative tests during in vivo experiment

\begin{tabular}{lcll}
\hline \multicolumn{2}{l}{ Prophylactic Test } & & \\
\hline Groups & Number of Animals & Treatment & Dosage \\
1 & 5 & Chloroquine diphosphate & $10 \mathrm{mg} / \mathrm{kg}$ \\
2 & 5 & Distilled water & $0.2 \mathrm{ml}$ \\
3 & 5 & aqueous plant extract & $100 \mathrm{mg} / \mathrm{kg}$ \\
4 & 5 & aqueous plant extract & $200 \mathrm{mg} / \mathrm{kg}$ \\
5 & 5 & aqueous plant extract & $400 \mathrm{mg} / \mathrm{kg}$ \\
\hline
\end{tabular}

\subsection{Acute toxicity test}

The acute toxicity test of aqueous crude extract of (ACEG) was carried out based on the calculated $\mathrm{LD}_{50}$ using a modified method described by Author et al.[18]. Groups of naive ICR mice ( 5 mice of each) were given the ACEG orally the following dosages; 100, 200 and $400 \mathrm{mg}$ per body weight $(\mathrm{kg})$ of the mice. Signs of toxicity were observed in the mice included but not limited to 
salivation, stretching the whole body, paw licking, anorexia, weakness, weight loss, respiratory distress and death within the first 4 hours. Subsequently, they were observed daily for 7 days to record any other symptoms.

\subsection{Anti-malarial drug}

The anti-malarial drug; Chloroquine diphosphate, was used as the positive control. It was used to study the in vivo drug susceptibility of PbANKA. The drug was mashed in a sterilized mortar and pestle, weighed and then made into a suspension using distilled water. This was then administered to the mice orally by gavage. The dosage of the drug, expressed in $\mathrm{mg} / \mathrm{kg}$ of body weight, was adjusted at the time of administration according to the weight of each mouse. The dose of $10 \mathrm{mg} / \mathrm{kg}$ was based on the ED90 of this drug on PbANKA infected mice.

\subsection{Statistical Analysis}

The results were presented as means and standard error of the mean (SEM). Statistical analysis was done using One-way ANOVA and was used to compare several treatment groups. Significant differences were considered at 95\% confidence levels, $\mathrm{p}<0.01$ and $\mathrm{p}<0.001$.

\section{Results}

Phytochemical screening of ethanolic extract yielded various degrees of secondary metabolites as shown in Table 2. Guiera senegalensis showed a very strong positive reaction for the presence of tannins, positive reaction for saponins, phenolic compounds, flavonoids and carbohydrates and trace presence of alkaloid. However, there was a negative reaction to cardiac glycoside.

Quantitative phytochemical analysis was further carried out to elicit the total phenolic and flavonoid content of $G$. senegalensis leaves ethanol extract as shown in Table 3. The Total phenolic content of the plant was $58 \mathrm{mg}$ (Gallic acid) per gram of the leaf extract, while the total flavonoid content was $36 \mathrm{mg}$ (Quercetin) per gram as well.

The study on the acute toxicity of extracts showed no observed toxicity on all White Wister mice at all the doses tested as seen in Table 4. There was no mortality recorded at $100 \mathrm{mg} / \mathrm{kg}, 200$ $\mathrm{mg} / \mathrm{kg}$ as well as $400 \mathrm{mg} / \mathrm{kg}$ of $G$. senegalensis extract on the animals.

The in vivo prophylactic screening of $G$. senegalensis extracts against PbANKA in albino Wister Mice (Table 5) showed a steady decline in the mean days of survival of the animals with increasing dosage of the extract. Although the highest dosage of the extract used $(400 \mathrm{mg} / \mathrm{kg}) \mathrm{had}$ the highest significant antiplasmodial activity $(0.66 \pm 0.05$ mean parasitemia), it had the least $\%$ inhibition and the least number of survival days. The dosage that recorded the highest $\%$ inhibition $(79 \%)$ against the parasites was $200 \mathrm{mg} / \mathrm{kg}$, followed by the positive control (76\%), then $100 \mathrm{mg} / \mathrm{kg}$ $(74 \%)$, and then $400 \mathrm{mg} / \mathrm{kg}(66 \%)$. The negative control (distilled water) was completely insensitive ( $0 \%$ inhibition) to the malaria parasite; thus, giving an optimum dosage of $200 \mathrm{mg} / \mathrm{kg}$ for prophylactic antiplasmodial/anti-malarial therapy.

The in vivo curative screening of the extract also exhibited anti-plasmodial properties as shown in Table 6 below. The standard drug Chloroquine diphosphate was used as the positive control in this study was observed to reduce parasitemia by $52 \%$. Conversely, G. senegalensis at $100 \mathrm{mg} / \mathrm{kg}$ and $400 \mathrm{mg} / \mathrm{kg}$ also elicited similar inhibitory patterns (46\% and $47 \%$ respectively) against the malaria parasite. The $200 \mathrm{mg} / \mathrm{kg}$ dosage of the extract had the highest inhibition against the parasite as well as the highest mean number of mice that survived. Also, after the acclimatization period of the experiment, the mice that were given doses of 100 and $400 \mathrm{mg} / \mathrm{kg}$ survived for 13.67 and 14.33 days respectively. The positive control treatment had the highest mean number of days of survival (17.33 days), while the negative control treatment was highly susceptible to the activity of the parasite, as they could not survive beyond the eight days of the experiment. 
The in vivo curative study had similar results with the prophylactic test in that at a dosage of $200 \mathrm{mg} / \mathrm{kg}$ of the extract, both studies recorded highest antiplasmodial/anti-malarial activity against P. berghei in the Wister Albino rats (Mus musqulus).

The calibration curves in Fig. $1(a, b)$ were used for the quantitative determination of the total phenolic and total flavonoid content.
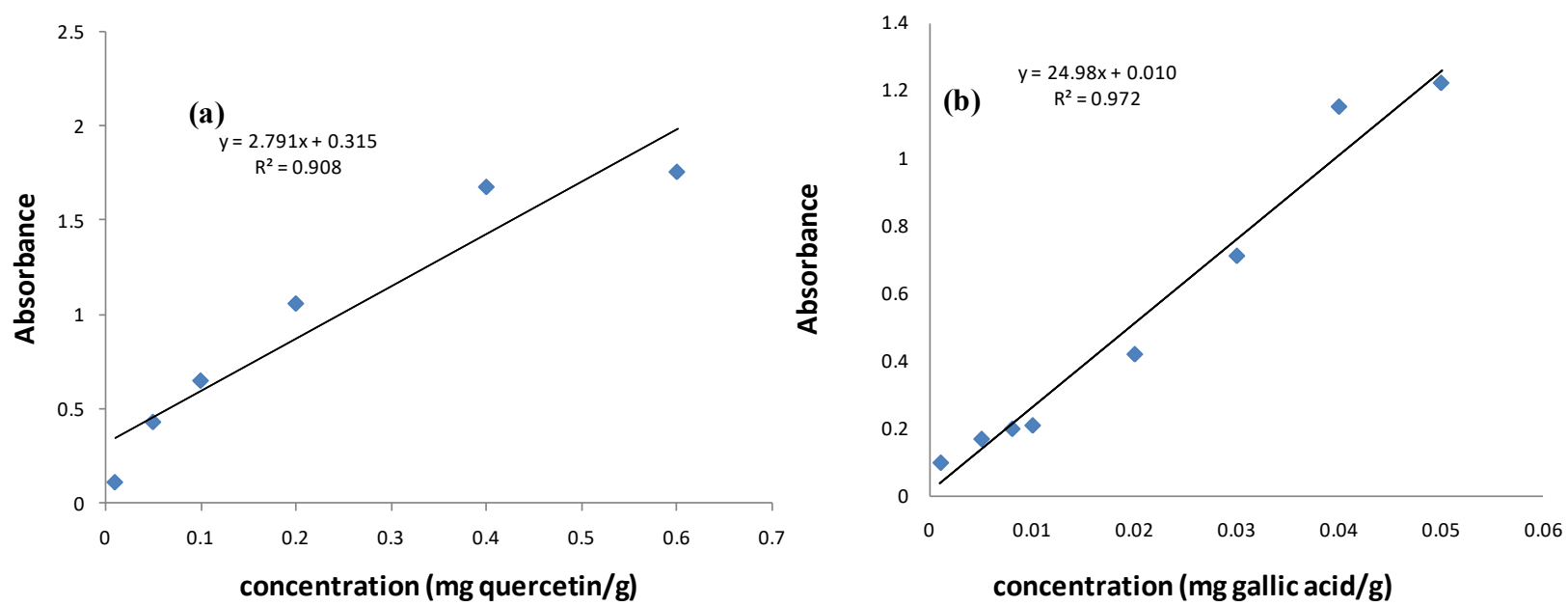

Figure 1: Standard calibration curve of (a) Quercetin for the determination of total flavonoid content; (b) Gallic acid for the determination of total phenolic content

Table 2: Phytochemical screening of ethanol extract of $G$. senegalensis

Phytochemical Test RESULT

\begin{tabular}{lc}
\hline Alkaloid & + \\
Carbohydrate & ++ \\
Flavonoid & ++ \\
Cardiac glycoside & - \\
Glycoside & - \\
Phenolic compounds & ++ \\
Saponins & ++ \\
Tannin & +++ \\
\hline strong positive, (++) positive, (+) Trace, (-) Negative
\end{tabular}

Table 3: Total phenolic and flavonoid content of Guiera senegalensis

\begin{tabular}{lll}
\hline Plant & $\begin{array}{l}\text { Phenolic content } \\
\text { (mg Gallic acid/g) }\end{array}$ & $\begin{array}{l}\text { Flavonoid content } \\
\text { (mg Quercetin/g) }\end{array}$ \\
\hline G. senegalensis & $58 \mathrm{mg}$ & $36 \mathrm{mg}$ \\
\hline
\end{tabular}


Table 4: Acute toxicity study of extracts on Wister Albino Rats

\begin{tabular}{cccc}
\hline \multicolumn{1}{c}{ Groups } & Dose (mg/kg) & Number of Mice & Mortality (\%) \\
\hline G. senegalensis & 100 & 5 & 0 \\
G. senegalensis & 200 & 5 & 0 \\
G. senegalensis & 400 & 5 & 0 \\
\hline
\end{tabular}

Table 5: Effect of extracts in the prophylactic treatment of Plasmodium berghei induced malaria

\begin{tabular}{|c|c|c|c|c|c|}
\hline Groups & Drugs & $\begin{array}{l}\text { Dose } \\
(\mathrm{mg} / \mathrm{kg})\end{array}$ & $\begin{array}{l}\text { Mean } \pm \text { SEM of } \\
\text { Parasitemia }\end{array}$ & $\begin{array}{l}\text { \% } \\
\text { inhibition }\end{array}$ & $\begin{array}{l}\text { Mean } \pm \text { SEM } \\
\text { of survival } \\
\text { days }\end{array}$ \\
\hline Negative control & Distilled water & $0.2 \mathrm{ml}$ & $0.00 \pm 0.00$ & 0 & $7.67 \pm 0.89$ \\
\hline Positive control & $\begin{array}{l}\text { Chloroquine } \\
\text { diphosphate }\end{array}$ & 10 & $0.76 \pm 0.04^{\mathbf{b}}$ & 76 & $20.33 \pm 0.33$ \\
\hline Leaf extract & $\begin{array}{l}\text { G. } \\
\text { senegalensis }\end{array}$ & 100 & $0.74 \pm 0.12^{\mathbf{b}}$ & 74 & $20.00 \pm 0.58$ \\
\hline Leaf extract & $\begin{array}{l}\text { G. } \\
\text { senegalensis }\end{array}$ & 200 & $0.79 \pm 0.06^{\mathbf{b}}$ & 79 & $19.0 \pm 1.16$ \\
\hline Leaf extract & $\begin{array}{l}\text { G. } \\
\text { senegalensis }\end{array}$ & 400 & $0.66 \pm 0.05^{\mathrm{a}}$ & 66 & $17.33 \pm 0.88$ \\
\hline
\end{tabular}

Table 6: Effect of ethanol extract of Guiera senegalensis in the curative treatment of Plasmodium berghei induced malaria

\begin{tabular}{llllll}
\hline Groups & Drugs & $\begin{array}{l}\text { Dose } \\
(\mathbf{m g} / \mathbf{k g})\end{array}$ & $\begin{array}{l}\text { Mean } \pm \text { SEM } \\
\text { of } \\
\text { Parasitemia }\end{array}$ & $\begin{array}{l}\text { \% } \\
\text { inhibition }\end{array}$ & $\begin{array}{l}\text { Mean } \pm \text { SEM of } \\
\text { survival days }\end{array}$ \\
\hline $\begin{array}{l}\text { Negative } \\
\text { Control }\end{array}$ & Distilled water & $0.2 \mathrm{ml}$ & $0.00 \pm 0.00$ & 0 & $7.67 \pm 0.88$ \\
$\begin{array}{l}\text { Positive control } \\
\text { Chloroquine }\end{array}$ & 10 & $0.52 \pm 0.08^{\mathrm{a}}$ & 52 & $17.33 \pm 1.45$ \\
$\begin{array}{l}\text { Plant extracts } \\
\text { Plant extracts }\end{array}$ & G. senegalensis & 100 & $0.46 \pm 0.09^{\mathrm{a}}$ & 46 & $13.67 \pm 0.88$ \\
Plant extracts & G. senegalensis & 200 & $0.80 \pm 0.07^{\mathrm{b}}$ & 80 & $16.00 \pm 2.08$ \\
\hline $\mathrm{a}=\mathrm{P}<0.01, \mathrm{~b}=\mathrm{p}<0.001, \mathrm{n}=5$ & 400 & $0.47 \pm 0.10^{\mathrm{a}}$ & 47 & $14.33 \pm 0.88$ \\
\hline
\end{tabular}

\section{Discussion}

This study focused on the antiplasmodial activity of Guiera senegalensis leaf extracts against Plasmodium berghei strain ANKA in Wister Albino Rats. It was carried out as a result of several reported cases of antibiotic resistance of the Malaria parasite, Plasmodium spp., against conventional therapies. The search for alternative antiplasmodial therapies from natural sources has been the aim of several recent anti-malarial research endeavours, of which extracts and drugs from plant materials have been of major concern [19]. Guiera senegalensis has been reported from earlier 
studies, as shown in Table 7, to possess healing properties against many diseases [20] including cough, respiratory congestion, fever [19] bronchial disorders [13], stomach pains and dysenteric diarrhoea [21] and malaria [22].

Table 7: Application of G. senegalensis extracts in treating various ailments in Senegal

\begin{tabular}{|l|l|l|}
\hline Plant part & Diseases & Extraction procedure \\
\hline \multirow{4}{*}{$\begin{array}{c}\text { G. senegalensis leaves } \\
\text { extract }\end{array}$} & Jaundice & Decoction of fresh leaves or soaked in water \\
\cline { 2 - 3 } & Abdominal pain & Decoction of fresh leaves or soaked in water \\
\cline { 2 - 3 } & Diabetes & Decoction of fresh leaves or soaked in water \\
\cline { 2 - 3 } & Hypertension & Decoction of fresh leaves or soaked in water \\
\cline { 2 - 3 } & Diarrhoea & Decoction of fresh leaves or soaked in water \\
\cline { 2 - 3 } & Malaria & Decoction of fresh leaves or soaked in water \\
\cline { 2 - 3 } powder & Joints problems & Decoction of fresh leaves or soaked in water \\
\cline { 2 - 3 } & Kidney diseases & Decoction of fresh leaves or soaked in water \\
\cline { 2 - 3 } & Constipation & Decoction of fresh leaves or soaked in water \\
\hline \multirow{5}{*}{ senegalensis roots } & Dermatitis & Powdered roots \\
\cline { 2 - 3 } & $\begin{array}{l}\text { Wounds including } \\
\text { diabetic wounds }\end{array}$ & Powdered roots \\
\cline { 2 - 3 } & $\begin{array}{l}\text { Rectum injury in } \\
\text { children }\end{array}$ & Powdered roots \\
\cline { 2 - 3 } & $\begin{array}{l}\text { Passage way injury after } \\
\text { parturition }\end{array}$ & Powdered roots \\
\hline
\end{tabular}

Adapted from Alshafei et al.[19]

These healing properties, as reported by these studies among others, therefore prompted the present investigation into its phytochemical constituents as well its activity against malaria parasite; Plasmodium berghei Strain ANKA in Wister albino rats.

In this study, the phytochemical analysis of the plant extracts revealed the presence of tannins, saponins, phenolic compounds, flavonoids, carbohydrates and alkaloids while there was a negative reaction for cardiac glycosides. This study corroborates the study of Alshafei et al. [19] who also reported similar results and found the plant to have alkaloids, flavonoids, terpenoids, tannins, carbohydrates, proteins, steroids and saponins present in the leaf extracts. The presence of these phytochemicals in the leaf extracts probably explain why the Tukolor people of Senegal include the leaves in their meals to enhance growth, increase body weight, enhance milk secretion in farm animals as well as enhance their reproductive ability [19]. Malaria, a deadly disease caused by the endoparasite Plasmodium sp., exhibits several clinical symptoms including fever, malaise, headache, vomiting, hallucinations, convulsions and even fatality in some cases. This parasite has been controlled with several synthetic antimalarials such as quinolones (Chloroquine diphosphate), Artesunate, Artemisinin, Lumefantrine etc., however, this parasite has repeatedly developed resistance to the majority of these conventional pharmaceuticals, so much that there is an urgent call to develop new, safe and effective therapies to combat this pandemic. This study serves as a step in the right direction in the search for a lasting solution to this menace, as the extracts of $G$. senegalensis used in this study showed highly significant antiplasmodial activity against PbANKA.

In the in-vitro prophylactic and curative studies on the antiplasmodial activity of extracts in Wister Albino rats, the extracts were able to inhibit the malaria parasite at various concentrations. This antiplasmodial activity observed is probably the reason why some locals employ the plant extracts in the treatment of malaria. The observed anti-plasmodic activity might have arisen as a result of the presence of tannins, flavonoids, saponins and other phytochemicals which have been shown by other studies to possess anti-bacterial properties [23,24,25]. This indicated that $G$. senegalensis has the potential of being the right therapy to successfully and naturally control PbANKA. 
In this study also, the presence of tannins in the leaf extracts of $G$. senegalensis was very reactive, and tannins have been reported to possess wounds and burns healing property [26,27]. A tea-like drink (decoction), taken by the people of Segue, in Senegal, made from the leaves of $G$. senegalensis is used for treating malaria attacks, severe diarrhoea and dysentery [28]. The main advantage of using plant extracts in treating health conditions is that they are relatively less expensive than the synthetic pharmaceuticals, yet possess profound therapeutic properties when used in treating debilitating diseases.

In the acute toxicity test carried out in this present study, extracts were found to be safe on all White Wister mice used, with no mortalities recorded at 100, 200 and $400 \mathrm{mg} / \mathrm{kg}$ of the body mass of the mice. These $\mathrm{LD}_{50}$ concentrations (dosages of $100,200,400 \mathrm{mg} / \mathrm{kg}$ ) of the extract used were chosen as recommended by the OECD (2001). This was quite notable as other researchers who also screened the aqueous extracts from its roots and leaves for toxicity found similar outcomes. The observed result is in agreement with the study of Mustofa et al. [29]. The lack of toxicity of the extract on the test animals in this study indicates the safety of $G$. senegalensis on mammalian tissues upon oral administration when used in the treatment of the parasite-mediated disease, malaria.

\section{Conclusion and Recommendation}

In this study, it was also observed that ethanol extract of Guiera senegalensis drastically reduced the level of Plasmodium berghei in Wister Albino rats across the administered doses and it had no toxic effect on them. The anti-plasmodial activity of the extract was highly significant and comparable with conventional anti-malarial drugs such as Chloroquine. This anti-plasmodial activity could be attributed to the presence of active phytochemicals such as tannins, saponins, anthraquinones and flavonoids etc. This explains why it has found its use in traditional medicine among the locals of tropical countries in the treatment of malaria, respiratory congestion, fever amongst others. It is therefore recommended that further studies should be carried on this plant species to elucidate the histopathological effects of each active ingredient in the extract in order to prepare a natural pharmaceutical product of high medicinal value.

\section{Conflict of Interest}

The authors declare no conflict of interest

\section{References}

[1] Y.J. Zhang et al., Antioxidant Phytochemicals for the Prevention and Treatment of Chronic Diseases, Molecules. 20 (2015) 21138-21156.

[2] A.P. Barbosa et al., Antidiabetic effect of the Chrysobalanus icaco L. aqueous extract in rats, J. Med Food. 16 (2013) 538-543.

[3] T. Yamada et al., Frequency of citrus fruit intake is associated with the incidence of cardiovascular disease: the Jichi Medical School cohort study, J Epidemiol 21 (2011) 169175.

[4] J. Mursu et al., Intake of fruit, berries, and vegetables and risk of type 2 diabetes in Finnish men: the Kuopio Ischaemic Heart Disease Risk Factor Study, Am J Clin Nutr 99 (2014) 328-333.

[5] P.A. Kager, Malaria control: constraints and opportunities, Tropical Medicine \& International Health. 7 (2002) 1042-1046.

[6] R.E. Cibulskis et al., Worldwide incidence of malaria in 2009: estimates, time trends, and a critique of methods, PLoS Medicine. 8 (2011) e1001142-e1001142. 
[7] G. Bourdy et al., Ethnopharmacology and malaria: new hypothetical leads or old efficient antimalarials?, Int. J. Parasitol 38 (2008) 33-41.

[8] B.B. Petrovska, Historical review of medicinal plants' usage, Pharmacognosy Reviews. 6 (2012) $1-5$.

[9] A.A. Biu et al., Phytochemistry, Toxicity and In Vitro Antitrypanosomal Efficacy of Crude Aqueous Extract of Guiera Senegalensis Stem Bark, Bangladesh Journal of Veterinary Medicine. 14 (2016) 93-97.

[10] S.O. Aniagu et al., Anti-diarrhoeal and ulcer-protective effects of the aqueous root extract of Guiera senegalensis in rodents, Journal of Ethnopharmacology. 97 (2005) 549-554.

[11] Y. Vaghasiya, R. Dave, S. Chanda, Phytochemical Analysis of Some Medicinal Plants from Western Region of India, Research Journal of Medicinal Plants. (2011) 567-576.

[12] Z. Males, M. Medić-Šarić, F. Bucar, Flavonoids of Guiera senegalensis J. F. GMEL. -Thinlayer Chromatography and Numerical Methods, Croatica Chemica Acta. 71 (1998) 69-79.

[13] W. Diatta et al., Experimental evidence of against cough activity of total alkaloids from Guiera senegalensis Lam. in guinea pig, Dakar Medical. 52 (2007) 130-134.

[14] N. Azas et al., Synergistic in vitro antimalarial activity of plant extracts used as traditional herbal remedies in Mali, Parasitol Res. 88 (2002) 165-171.

[15] W. Health Organization, WHO Guidelines on Good Agricultural and Collection Practices (GACP) for Medicinal Plants, 2003.

[16] S. Sasidharan et al., Extraction, isolation and characterization of bioactive compounds from plants' extracts, African Journal of Traditional, Complementary, and Alternative Medicines. 8 (2010) 1-10.

[17] K.N. Agbafor, N. Nwachukwu, Phytochemical Analysis and Antioxidant Property of Leaf Extracts of Vitex doniana and Mucuna pruriens, Biochemistry Research International. 2011 (2011) 4.

[18] H.Y. Bako et al., Toxicity Studies of Aqueous, Methanolic and Hexane Leaf Extracts of Guiera Senegalensis In Rats, International Journal of Scientific \& Engineering Research. 5(10) (2014) 1338-1347.

[19] N.K. Alshafei, S.M. Ahmed, A. Nour, Preliminary Observations on the Uses of Guiera Senegalensis as a Traditional Medicinal Plants in Western Kordufan, Sudan International Journal of Applied and Pure Science and Agriculture. 2 (2016) 42-48.

[20] A.A. Biu et al., Phytochemistry, Toxicity and In Vitro Antitrypanosomal Efficacy of Crude Aqueous Extract Of Guiera Senegalensis Stem Bark, Bangladesh Journal of Veterinary Medicine 14 (2016) 93-97.

[21] S.O. Aniagu et al., Anti-diarrhoeal and ulcer-protective effects of the aqueous root extract of Guiera senegalensis in rodents, J. Ethnopharmacol 97 (2005) 549-554.

[22] N. Azas et al., Synergistic in vitro antimalarial activity of plant extracts used as traditional herbal remedies in Mali, Parasitology Research. 88 (2002) 165-171.

[23] S. Jahani et al., Investigating the Antibacterial Effects of Plant Extracts on Pseudomonas aeruginosa and Escherichia coli, Int. J. Infect. 3 (2016) e34081.

[24] P.O. Osadebe, S.E. Ukwueze, A Comparative Study of the Phytochemical And Anti-Microbial Properties of the Eastern Nigerian Specie of African Mistletoe (Loranthus micranthus) Sourced From Different Host Trees, Bio-Research. 2 (2004) 18-23. 
[25] J. Ogbeba, F.O. Iruolaje, B.A. Dogo, Antimicrobial Efficacy of Guiera Senegalensis and Prosopis Africana Leave Extract on Some Bacterial Pathogens, European Journal of Biology and Medical Science Research. 5 (2017) 27-36.

[26] B. Franke-Fayard et al., Simple and sensitive antimalarial drug screening in vitro and in vivo using transgenic luciferase expressing Plasmodium berghei parasites, Int. J. Parasitol. 38 (2008) 1651-1662.

[27] C.O. Eleazu et al., Comparative Study of the Phytochemical Composition of the Leaves of Five Nigerian Medicinal Plants, Journal of Biotechnology and Pharmaceutical Research. 3 (2012) 42-46.

[28] K. Rajnarayana et al., Bioflavonoids Classification, Pharmacological, Biochemical Effects and Therapeutic Potential, Indian Journal of Pharmacology. 33 (2001) 2-16.

[29] S.E. Mustofa, S. Wahyuono, In vitro and in vivo antiplasmodial activity and cytotoxicity of extracts of Phyllanthus niruri L. herbs traditionally used to treat malaria in Indonesia, Southeast Asian J. Trop Med Public Health. 38 (2007) 609-615. 